Article

\title{
The Study of a Multicriteria Decision Making Model for Wave Power Plant Location Selection in Vietnam
}

\author{
Chia-Nan Wang ${ }^{1,2, *}$, Nguyen Van Thanh ${ }^{3}$ and Chih-Chiang Su ${ }^{1,4, *}$ \\ 1 Department of Industrial Engineering and Management, National Kaohsiung University of Science and \\ Technology, Kaohsiung 80778, Taiwan \\ 2 Hi-P International Limited, Singapore 609926, Singapore \\ 3 Department of Logistics and Supply Chain Management, Hong Bang International University, \\ Ho Chi Minh City 72320, Vietnam; thanhnv@hiu.vn \\ 4 Metal Industries and Research Centre, Kaohsiung 83158, Taiwan \\ * $\quad$ Correspondence: cn.wang@nkust.edu.tw (C.-N.W.); i107143102@nkust.edu.tw (C.-C.S.)
}

Received: 22 August 2019; Accepted: 18 September 2019; Published: 23 September 2019

check for Abstract: With about a $7 \%$ average annual economic growth rate in Vietnam, the demand for electricity
production is increasing, and, with more than $3000 \mathrm{~km}$ of coastline, the country has great potential for
developing wave energy sources to meet such electricity production. This energy source, also known
as renewable energy, comes from tides, wind, heat differences, flows, and waves. Both wind and wave
energy are considered to have the most potential for energy sources in Vietnam. Just as hydropower
projects are controversial due to depleting water resources and regulating floods, nuclear power
projects cause safety concerns. To overcome this problem, Vietnamese scientists are considering using
abundant wave energy resources for electricity. Nowadays, the ocean energy sector offers many new
technologies to help minimize carbon dioxide emissions $\left(\mathrm{CO}_{2}\right)$ in the living environment. Further,
many countries already have wave power plants. In this research, an integrated model, combining
the fuzzy analytical network process (FANP) and the technique for order of preference by similarity
to ideal solution (TOPSIS), is proposed for wave energy plant location selection. As a result, Con
Co (SITE3) is determined the best site for wave energy production. The primary aim of this study is
to provide insight into site selection problems for renewable energy investments of Vietnam. The
contribution of this research is to propose a fuzzy multiple-criteria decision-making (MCDM) model
for site selection in the renewable energy sector. The proposed model also can address different
complex problems in location selection; it is also a flexible design model for considering the evaluation
criteria; further, it is applicable to site selection of other renewable energies in the world.

Keywords: renewable energy; wave energy; fuzzy logics; MCDM; FANP; TOPSIS

\section{Introduction}

The oceans form one of the largest yet least explored renewable energy sources on earth. Ocean energy has the potential to provide a substantial amount of renewable and reliable energy all over the world. Different technologies employ different strategies for harvesting that energy. The main sources of ocean energy are tidal streams, ocean currents, tidal range (rise and fail), waves, ocean thermal energy, and salinity gradients [1,2].

Vietnam has a sea area of about 1 million $\mathrm{km}^{2}$, stretching $3260 \mathrm{~km}$ along the length of the country, which is a favorable factor for developing energy from the sea. The calculation results show that wave energy along the coastal strip of Vietnam is very high. The weakest average energy flow reaches $15 \mathrm{~kW} / \mathrm{m}$; the strongest $30 \mathrm{~kW} / \mathrm{m}$ [3].

According to calculations, if a wave has a height of $1 \mathrm{~m}$, at a length of about $1.8 \mathrm{~km}$ of coast, it is possible to create an energy source equal to 35,000 horsepower [4]. Vietnam has the ability to 
utilize an extra source of renewable energy, that is, energy from ocean waves. However, one of the major problems with wave energy is that it is location-dependent, where many factors that increase its utilization potential are dependent on the feasibility of the locations. In this research, the authors propose a new fuzzy multiple-criteria decision-making (MCDM) method, which is both objective and cognitive, to identify suitable locations where the optimal amount of wave energy can be produced in Vietnam. Site selection is an important issue for the MCDM model. Many studies have applied the MCDM approach to various fields in the energy sector, e.g., J. Huang et al. [5]; E. Løken et al. [6], Soumya Ghosh et al. [7]. Utilizing any decision-making technique involving numerical analysis of alternatives requires three steps: [6].

1. Determine the relevant factors and options.

2. Attach numerical measures to the relative importance of the factors and to the impacts of the options on these factors.

3. Process the numerical values to determine a ranking of each option.

In the first stage of this research, all criteria affecting location selection were determined by experts and literature reviews, and fuzzy analytical network process (FANP) method was utilized to identify the weight of all criteria in the second stage. The technique for order of preference by similarity to ideal solution (TOPSIS) is a multicriteria decision analysis method, which was used for ranking potential sites in the final stage.

\section{Literature Review}

Soumya Ghosh et al. [8] proposed an artificial neural network model (ANN) and MCDM models for selecting suitable location for developing of the location suitability index for wave energy production. Tilottama et al. [9] applied an Analytic Hierarchy Process (AHP) model for wave power plant location selection. This study introduces a new way to identify location where maximum utilization of ocean energy resources can be possible with minimum expenditure.

S. Astariz et al. [10] proposed new approach to identifying suitable sites for co-located wave and wind farms. The goal of this research is to develop a new model to defining suitable location for co-located wave and wind farms. Cigdem Ozkan et al. [11] used observed data to estimate the ocean wave power available in coastal Florida. CN. Wang et al. [12] proposed an MCDM model including fuzzy analytical hierarchy process (FAHP), data envelopment analysis (DEA), and the TOPSIS to find the optimal location for solar plant site selection in Vietnam. This research is part of the evolution of a new model that is flexible and practical for decision makers and this work also provides useful guidelines for renewable energy sector.

Özge Pınar Akkaş et al. [13] applied an MCDM model for solar power plant location selection in the Central Anatolian Region of Turkey. In this research, various suggestions are identified about site selection, which is an important step in the photovoltaic power systems (PVPS) establishment. Hence, the factors for selecting the appropriate location are analyzed by the MCDM model. Laura Zubiate et al. [14] introduced a new approach for site selection for wave energy projects. In this study, the authors integrated the data as layers into a GIS (Geographic Information Systems) tool, given the spatial nature of the project. This tool will provide an accurate and convenient visual aid for choosing a suitable area.

M. Vasileiou et al. [15] combined an MCDM model and GIS for site selection of hybrid offshore wind and wave energy systems in Greece. Those that are unsuitable for the deployment of HOWiWaES marine areas are determined through the GIS database at the first step of this research. Then, the AHP model is applied for evaluating and ranking all criteria in the second step. Chang-Lin Yang et al. [16] applied a ANP/AHP model for location selection. A. Azizi et al. [17] applied hybrid ANP and decision making trial and evaluation (DEMATEL) methods in a GIS environment. DEMATEL is used to identify the factor's relationships. The weights of the criteria were calculated using an ANP model and the overlaying process was identified in GIS environment. 
Dragan Pamucar et al. [18] applied a GIS multi-criteria hybrid model, an approach based on fuzzy and rough numbers for wind farm site selection. Saeedeh Nasehi et al. [19] used a hybrid model including fuzzy GIS and ANP for wind power plant location selection. The primary goal of this research was the location selection based on the fuzzy logic and weighted linear combination (WLC).

Nazmul Ahsan et al. [20] proposed fuzzy ANP extent analysis to assess and select locations for wind power plants. The primary goal of this research is to present a comprehensive pairwise comparison of factors and subfactors for selecting the optimal location for wind power plant. A.K Jaiswal et al. [21] proposed geospatial multicriteria decision making based site sustainability analysis for solid waste disposal using a TOPSIS model. I. Konstantinos, et al. [22] proposed a spatial decision support system framework for the evaluation of biomass energy production locations: case study in the regional unit of Drama, Greece.

Wang et al. [23] proposed an MCDM model for wind power plant location section in Vietnam. In this research, the author applied a hybrid model by using FAHP and TOPSIS for finding optimal locations for wind power plants. I. Konstantinos et al. [24] proposed decision support system methodology for selecting wind farm installation locations using AHP and TOPSIS. The application of this methodology can help decision makers to easily overcome conflicting parameters and propose optimal solutions which are acceptable from citizens and stake holders while at the same time are economical and environmentally friendly. B. Asl-Rousta [25] applied a TOPSIS model to aggregate different efficiency criteria and to discriminate between the models. Results show the usefulness of the proposed MCDA-based approach to rank different alternatives (settings) of model calibration. M. Erbaş et al. [26] applied a GIS-based fuzzy multi-criteria decision analysis for optimal siting of electric vehicle charging stations.

As shown in the literature review, the MCDM model has been applied to various fields of science and technology, and its use has increased over the years. One of the areas in which this model has been applied is the location selection process, but few have considered this issue in wave energy power plant location selection. This is the main reason why this study proposes an MCDM model for wave power plant site selection. The primary goal of this research is to provide an MCDM model and detail the decision-making steps in site selection in the renewable energies sector. The goal of this study is also to propose useful guidelines for location selection in other fields.

\section{Methodology}

\subsection{Research Development}

In this work, the authors proposed a fuzzy multicriteria decision-making (FMCDM) model for analyzing a suitable site for wave energy production via FANP and TOPSIS models. This research involves three main steps, as shown in Figure 1.

Step 1: The authors identified all criteria and sub-criteria effects in regard to the wave power plant location selection process through experts and literature reviews.

Step 2: The FANP was proposed to identify the weight of all criteria in the second stage.

Step 3: The technique for order of preference by similarity to an ideal solution (TOPSIS) is an MCDM method. In this research, TOPSIS was used for ranking potential sites in the final stage. 


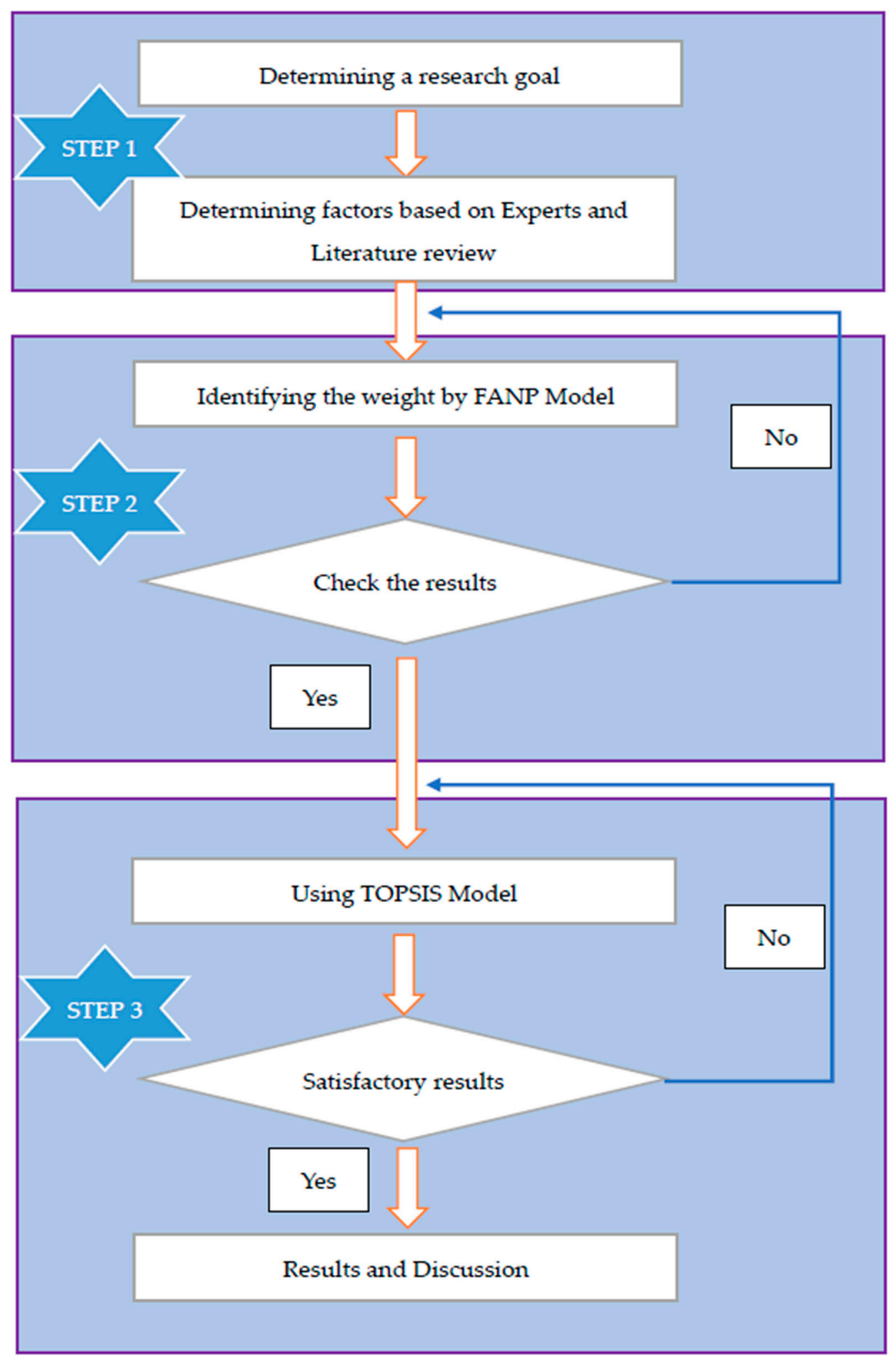

Figure 1. Research methodology.

\subsection{Basic Model Theory}

\subsubsection{Fuzzy Analytic Network Process (FANP)}

A fuzzy set is a class of objects with continuity of membership levels [27]. Such a set is characterized by a member function, which assigns each object a member level between $[0,1]$. The TFN can be 
defined as $(q, w, e), q, w$ and $e(q \leq w \leq e)$ are parameters, indicating the smallest, the promising, and the largest value in TFN. TFN are shown in Figure 2.

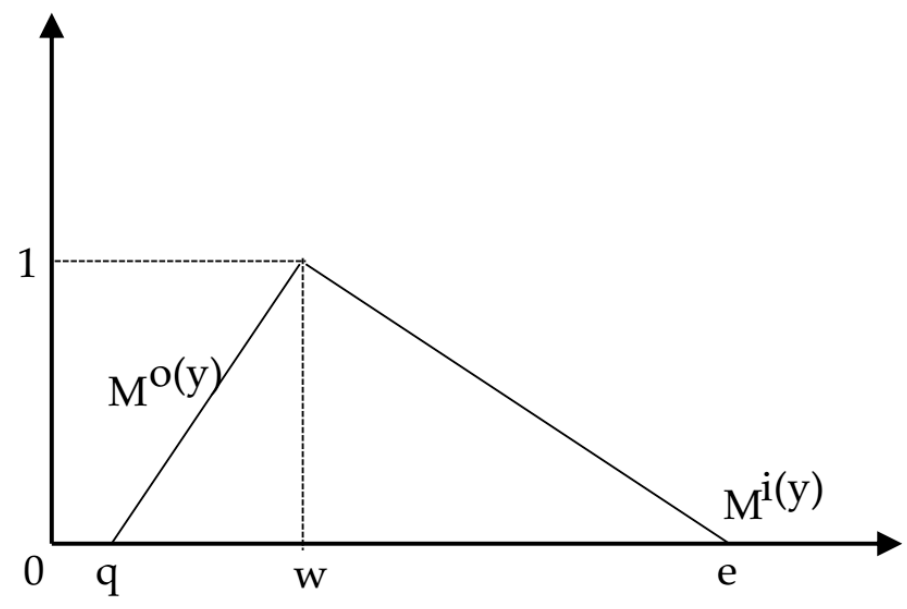

Figure 2. Triangular Fuzzy Number.

Triangular Fuzzy Number: a fuzzy number $\widetilde{M}=(q, w, e)$ is called triangular fuzzy number if its membership function is given by:

$$
\mu\left(\frac{x}{\widetilde{M}}\right)=\left\{\begin{array}{cc}
0, & x<w \\
\frac{x-q}{w-q} & q \leq x \leq w \\
\frac{e-x}{e-w} & w \leq x \leq e \\
0, & x>e
\end{array}\right.
$$

Consider two positive triangular fuzzy numbers $M_{1}=\left(q_{1}, w_{1}, e_{1}\right)$ and $M_{2}=\left(q_{2}, w_{2}, e_{2}\right)$.

The basic calculations of fuzzy numbers are shown in:

$$
\widetilde{M}=\left(M^{o(y)}, M^{i(y)}\right)=[q+(w-q) y, e+(w-e) y], y \in[0,1] .
$$

$o(y), i(y)$ indicates both the left side and the right side of a fuzzy number as:

$$
\begin{gathered}
\left(q_{1}, w_{1}, e_{1}\right)+\left(q_{2}, w_{2}, e_{2}\right)=\left(q_{1}+q_{2}, w_{1}+w_{2}, e_{1}+e_{2}\right) \\
\left(q_{1}, w_{1}, e_{1}\right)-\left(q_{2}, w_{2}, e_{2}\right)=\left(q_{1}-q_{2}, w_{1}-w_{2}, e_{1}-e_{2}\right) \\
\left(q_{1}, w_{1}, e_{1}\right) \times\left(q_{2}, w_{2}, e_{2}\right)=\left(q_{1} \times q_{2}, w_{1} \times w_{2}, e_{1} \times e_{2}\right) \\
\frac{\left(q_{1}, w_{1}, e_{1}\right)}{\left(q_{2}, w_{2}, e_{2}\right)}=\left(q_{1} / q_{2}, w_{1} / w_{2}, e_{1} / e_{2}\right) .
\end{gathered}
$$

ANP is a development of AHP model [24]. The model of ANP is in the form of a network hence we can see the interactions between each element on the same factor, or the elements of different factor. - Calculate Consistency Index (CI):

$$
C I=(\lambda \max -q) /(q-1)
$$

where:

\section{CI: Consistency Index}

$q$ : is the number of compared elements.

- Calculate the Consistency Ratio $(C R)$, using a random index as following:

$$
\text { CR: CI/UI, }
$$


where: $U I=$ random index ( $C I$ of randomly generated pairwise comparison matrix), random index are shown in Table 1.

Table 1. Random Index.

\begin{tabular}{cc}
\hline Matrix Size (q) & UI Value \\
\hline 1.0 & 0.00 \\
2.0 & 0.00 \\
3.0 & 0.58 \\
4.0 & 0.90 \\
5.0 & 1.12 \\
6.0 & 1.24 \\
7.0 & 1.32 \\
8.0 & 1.41 \\
9.0 & 1.45 \\
10.0 & 1.49 \\
\hline
\end{tabular}

3.2.2. Technique for Order Preference by Similarity to an Ideal Solution (TOPSIS)

The results of the analysis in some studies that used the TOPSIS method show that quality evaluation indicators affect the results of the evaluation, hence the selection of precise indicators is very important [25-27].

Determining TOPSIS needs performance ranking in every Ai option over every normalized Cj factor. This can be seen from the formula below:

$$
e_{i j}=\frac{X_{i j}}{\sqrt{\sum_{i=1}^{m} X_{i j}^{2}}},
$$

with $i=1,2, \ldots m$; and $j=1,2, \ldots n$.

Calculating the normalized weighted decision matrix

$$
S_{i j}=W_{i} e_{i j}
$$

with $i=1,2, \ldots, m$ and $j=1,2, \ldots, n$.

Calculating positive ideal solution (PIS) $A^{+}$matrix and negative ideal solution (NIS) $A^{-}$matrix.

$$
\begin{aligned}
A^{+} & =s_{1}^{+}, s_{2}^{+}, \ldots, s_{n}^{+} ; \\
A^{-} & =s_{1}^{-}, s_{2}^{-}, \ldots, s_{n}^{-} ;
\end{aligned}
$$

where: $s_{j}^{+}$is $\operatorname{Max} s_{i j}$ if $j$ is an advantage factor. Max $s_{i j}$ if $j$ is a cost factor. $s_{j}^{-}$Is Min $s_{i j}$ if $j$ is an advantage factor. Min $s_{i j}$ if $j$ is a cost factor.

Identifying the gap between the values of each options with PIS matrix and NIS matrix.

Options to positive ideal solution (PIS).

$$
D_{i}^{+}=\sqrt{\sum_{j=1}^{m}\left(s_{i}^{+}-s_{i j}\right)^{2}} ; \quad i=1,2, \ldots, m
$$

Options to negative ideal solution (NIS).

$$
D_{i}^{-}=\sqrt{\sum_{j=1}^{m}\left(s_{i j}-s_{i}^{-}\right)^{2}} ; \quad i=1,2, \ldots, m,
$$

where $D_{i}^{+}$is the distance to the PIS for I option and $D_{i}^{-}$is the distance to the NIS. 
Calculating the preference value for every alternative $\left(G_{i}\right)$

$$
G_{i}=\frac{D_{i}^{-}}{D_{i}^{-}+D_{i}^{+}} \quad i=1,2, \ldots, m .
$$

\section{Case Study}

Ocean waves, with their vast widths, contain significant energy resources. Energy density in waves is high compared with other renewable energy sources, e.g., wind and solar energy. Just less than $0.1 \%$ of the ocean's renewable energy is converted into electricity, which can satisfy more than five times the current global electricity demand. The World Energy Commission (WEC) estimates that the global wave energy market is $\sim 5.5 \mathrm{TWh} /$ year; in the future, it will exceed $2000 \mathrm{TWh}$. Many countries around the world have put into practice many wave-power-generating stations, with capacities ranging from a few dozen to several hundred $\mathrm{kW}$ to several MW, providing electricity for residential areas, especially for offshore islands [28].

As with other types of renewable energy resources, wave energy is invaluable and environmentally friendly. Technology to exploit ocean energy contributes to minimizing $\mathrm{CO}_{2}$ emissions into the living environment. In this case study, the authors considered eight potential locations for building a wave power plant in Vietnam. These locations are judged to be highly effective based on natural and socioeconomic conditions. Eight potential locations are able to invest in wave power plants, as shown in Table 2.

Table 2. List of 10 potential locations.

\begin{tabular}{ccc}
\hline No. & Name & Symbol \\
\hline 1 & Co To Island & SITE1 \\
2 & Bach Long Vi Island & SITE2 \\
3 & Con Co & SITE3 \\
4 & Vanh Rai Bay & SITE4 \\
5 & Phu Qui & SITE5 \\
6 & Cu Lao Cham & SITE6 \\
7 & Ha Long Bay & SITE7 \\
8 & Hon Me & SITE8 \\
\hline
\end{tabular}

Finding the best site for building a wave power farm is an important criterion affecting the time at which the project reaches completion. In order to select an optimal location, the decision-maker must first understand the criteria of location evaluation. Based on experts and literature reviews, a decision-maker has to consider four main criteria, i.e., energy resources, location suitability, environment suitability, social suitability. The hierarchy of the objectives of this study is shown in Table 3. 
Table 3. The hierarchy of the objectives.

\begin{tabular}{|c|c|c|c|}
\hline Main Criteria & Sub-Criteria & Experts/Literature Review & Symbol \\
\hline \multirow{13}{*}{$\begin{array}{l}\text { * Energy resource; } \\
\text { * Location suitability; } \\
\text { * Environment suitability; } \\
\text { * Social Suitability. }\end{array}$} & Wave height & $\begin{array}{l}\text { Chakraborty et al. } \\
\text { Soumya Ghosh et al. } \\
\text { Experts }\end{array}$ & WAH \\
\hline & $\begin{array}{c}\text { Distant between two } \\
\text { waves }\end{array}$ & $\begin{array}{l}\text { Soumya Ghosh et al. } \\
\text { Experts }\end{array}$ & DBW \\
\hline & Number of waves & $\begin{array}{l}\text { Soumya Ghosh et al. } \\
\text { Experts }\end{array}$ & NWA \\
\hline & Wind speed & $\begin{array}{l}\text { Chakraborty et al. } \\
\text { Soumya Ghosh et al. } \\
\text { Experts }\end{array}$ & WSP \\
\hline & Wind duration & $\begin{array}{l}\text { Chakraborty et al. } \\
\text { Experts }\end{array}$ & WDU \\
\hline & Depth of the Ocean & $\begin{array}{l}\text { Chakraborty et al. } \\
\text { Soumya Ghosh et al. Experts }\end{array}$ & DTS \\
\hline & Turbulence & $\begin{array}{c}\text { Soumya Ghosh et al. } \\
\text { Experts }\end{array}$ & TBL \\
\hline & Water quality & $\begin{array}{l}\text { Soumya Ghosh et al. } \\
\text { Experts }\end{array}$ & WQU \\
\hline & Coastal erosion & $\begin{array}{l}\text { Soumya Ghosh et al. } \\
\text { Experts }\end{array}$ & $\mathrm{COE}$ \\
\hline & Shipping density & $\begin{array}{l}\text { Soumya Ghosh et al. } \\
\text { Experts }\end{array}$ & SHD \\
\hline & Protection law & Experts & PRL \\
\hline & Labor resource & Experts & LBR \\
\hline & Safety conditions & Experts & SAC \\
\hline
\end{tabular}

A fuzzy comparison matrix for GOAL from the FANP approaches is shown in Table 4.

Table 4. Fuzzy comparison matrices for GOAL.

\begin{tabular}{ccccc}
\hline Criteria & $\begin{array}{c}\text { Energy Resource } \\
\text { (ER) }\end{array}$ & $\begin{array}{c}\text { Environment } \\
\text { Suitability (ES) }\end{array}$ & $\begin{array}{c}\text { Location } \\
\text { Suitability (LS) }\end{array}$ & $\begin{array}{c}\text { Social Suitability } \\
\text { (SS) }\end{array}$ \\
\hline Energy resource (ER) & $(1,1,1)$ & $(1,2,3)$ & $(3,4,5)$ & $(2,3,4)$ \\
Environment suitability & $(1 / 3,1 / 2,1)$ & $(1,1,1)$ & $(1,2,3)$ & $(2,3,4)$ \\
(ES) & $(1 / 5,1 / 4,1 / 3)$ & $(1 / 3,1 / 2,1)$ & $(1,1,1)$ & $(1 / 4,1 / 3,1 / 2)$ \\
Location suitability (LS) & $(1 / 4,1 / 3,1 / 2)$ & $(1 / 4,1 / 3,1 / 2)$ & $(4,3,2)$ & $(1,1,1)$ \\
Social Suitability (SS) & & & & \\
\hline
\end{tabular}

The authors obtain the coefficients $\alpha=0.5$ and $\beta=0.5$ (Tang and Beyond). $\alpha$ represents the uncertain environment conditions, while $\beta$ represents the attitude of the evaluator is fair.

$$
\begin{gathered}
\mathrm{g}_{0.5,0.5}\left(\overline{a_{E R, S S}}\right)=[(0.5 \times 2.5)+(1-0.5) \times 3.5]=3 \\
\mathrm{f}_{0.5}\left(\mathrm{~L}_{\mathrm{ER}, \mathrm{SS}}\right)=(3-2) \times 0.5+2=2.5 \\
\mathrm{f}_{0.5}\left(\mathrm{U}_{\mathrm{ER}, \mathrm{SS}}\right)=4-(4-3) \times 0.5=3.5 \\
\mathrm{~g}_{0.5,0.5}\left(\overline{a_{S S, E R}}\right)=1 / 3 .
\end{gathered}
$$

The real number priority when comparing the main criteria pairs are shown in Table 5. 
Table 5. Real number priority.

\begin{tabular}{ccccc}
\hline & $\begin{array}{c}\text { Energy Resource } \\
\text { (ER) }\end{array}$ & $\begin{array}{c}\text { Environment } \\
\text { Suitability (ES) }\end{array}$ & $\begin{array}{c}\text { Location } \\
\text { Suitability (LS) }\end{array}$ & $\begin{array}{c}\text { Social Suitability } \\
\text { (SS) }\end{array}$ \\
\hline Energy resource (ER) & 1 & 2 & 4 & 3 \\
Environment suitability (ES) & $1 / 2$ & 1 & 2 & 3 \\
Location suitability (LS) & $1 / 4$ & $\frac{1}{2}$ & 1 & $1 / 3$ \\
Social Suitability (SS) & $1 / 3$ & $1 / 3$ & 3 & 1 \\
\hline
\end{tabular}

For calculating the maximum individual value as following:

$$
\begin{aligned}
& \text { PO1 }=(1 \times 2 \times 4 \times 3)^{1 / 4}=2.21 \\
& \mathrm{PO} 2=(1 / 2 \times 1 \times 2 \times 3)^{1 / 4}=1.32 \\
& \text { PO3 }=(1 / 4 \times 1 / 2 \times 1 \times 1 / 3)^{1 / 4}=0.45 \\
& \mathrm{PO} 4=(1 / 3 \times 1 / 3 \times 3 \times 1)^{1 / 4}=0.76 \\
& \sum \mathrm{PO}=\mathrm{PO} 1+\mathrm{PO} 2+\mathrm{PO} 3+\mathrm{PO} 4=4.74 \\
& \omega_{1}=\frac{2.21}{4.74}=0.47 \\
& \omega_{2}=\frac{1.32}{4.74}=0.28 \\
& \omega_{3}=\frac{0.45}{4.74}=0.09 \\
& \omega_{4}=\frac{0.76}{4.74}=0.16 \\
& {\left[\begin{array}{cccc}
1 & 2 & 4 & 3 \\
1 / 2 & 1 & 2 & 3 \\
1 / 4 & 1 / 2 & 1 & 1 / 3 \\
1 / 3 & 1 / 3 & 3 & 1
\end{array}\right] \times\left[\begin{array}{l}
0.47 \\
0.28 \\
0.09 \\
0.16
\end{array}\right]=\left[\begin{array}{l}
1.87 \\
1.18 \\
0.48 \\
0.68
\end{array}\right]} \\
& {\left[\begin{array}{l}
1.87 \\
1.18 \\
0.48 \\
0.68
\end{array}\right] /\left[\begin{array}{l}
0.47 \\
0.28 \\
0.09 \\
0.16
\end{array}\right]=\left[\begin{array}{c}
4.0 \\
4.2 \\
4.44 \\
4.25
\end{array}\right]}
\end{aligned}
$$

Based on number of main criteria, the authors get $n=4, \lambda_{\max }$ and CI are calculated as following:

$$
\begin{gathered}
\lambda_{\text {max }}=\frac{4.0+4.2+4.44+4.25}{4}=4.23, \\
C I=\frac{\lambda_{\max }-n}{n-1}=\frac{4.23-4}{4-1}=0.08 .
\end{gathered}
$$

To calculate $C R$ value, we get $R I=0.9$ with $n=4$.

$$
C R=\frac{C I}{R I}=\frac{0.08}{0.9}=0.0889 .
$$

As $C R=0.0889 \leq 0.1$, we did not need to re-evaluate. The weight of all sub-criteria are shown in Table 6. 
Table 6. The weight of sub-criteria.

\begin{tabular}{ccc}
\hline No & Sub-Criteria & Weight \\
\hline 1 & WAH & 0.0936 \\
2 & DBW & 0.0895 \\
3 & NWA & 0.1517 \\
4 & WSP & 0.0358 \\
5 & WDU & 0.0530 \\
6 & DTS & 0.0492 \\
7 & TBL & 0.0765 \\
8 & WQU & 0.0612 \\
9 & COE & 0.0636 \\
10 & SHD & 0.0669 \\
11 & PRL & 0.1040 \\
12 & LBR & 0.1119 \\
13 & SAC & 0.0432 \\
\hline
\end{tabular}

Based on the weight of all sub-criteria defined by the FANP model, the TOPSIS approach was utilized to identify the score of all potential locations. The normalized matrix and normalized weight matrix are shown in Tables 7 and 8 .

Table 7. Normalized matrix.

\begin{tabular}{ccccccccc}
\hline & SITE1 & SITE2 & SITE3 & SITE4 & SITE5 & SITE6 & SITE7 & SITE8 \\
\hline WAH & 0.3219 & 0.3678 & 0.4138 & 0.4138 & 0.3219 & 0.2759 & 0.3678 & 0.3219 \\
DBW & 0.3225 & 0.3686 & 0.3686 & 0.3225 & 0.3686 & 0.4147 & 0.2765 & 0.3686 \\
NWA & 0.3182 & 0.3636 & 0.3636 & 0.3636 & 0.3636 & 0.3182 & 0.4091 & 0.3182 \\
WSP & 0.3581 & 0.3134 & 0.3581 & 0.3581 & 0.4029 & 0.3581 & 0.3581 & 0.3134 \\
WDU & 0.2857 & 0.3333 & 0.3333 & 0.3810 & 0.3810 & 0.3333 & 0.4286 & 0.3333 \\
DTS & 0.3629 & 0.4082 & 0.3629 & 0.3175 & 0.4082 & 0.3175 & 0.3175 & 0.3175 \\
TBL & 0.4224 & 0.3285 & 0.3755 & 0.3285 & 0.3285 & 0.3755 & 0.3285 & 0.3285 \\
WQU & 0.3285 & 0.3755 & 0.3285 & 0.3285 & 0.4224 & 0.3285 & 0.3755 & 0.3285 \\
COE & 0.3962 & 0.3522 & 0.3522 & 0.3522 & 0.3962 & 0.3082 & 0.3522 & 0.3082 \\
SHD & 0.3392 & 0.3392 & 0.3392 & 0.3876 & 0.2907 & 0.4361 & 0.3392 & 0.3392 \\
TOP & 0.4224 & 0.3285 & 0.3755 & 0.3285 & 0.3285 & 0.3755 & 0.3285 & 0.3285 \\
PRL & 0.3285 & 0.3755 & 0.3285 & 0.3285 & 0.4224 & 0.3285 & 0.3755 & 0.3285 \\
LBR & 0.3962 & 0.3522 & 0.3522 & 0.3522 & 0.3962 & 0.3082 & 0.3522 & 0.3082 \\
\hline
\end{tabular}

Table 8. Normalized weight matrix.

\begin{tabular}{ccccccccc}
\hline & SITE1 & SITE2 & SITE3 & SITE4 & SITE5 & SITE6 & SITE7 & SITE8 \\
\hline WAH & 0.0301 & 0.0344 & 0.0387 & 0.0387 & 0.0301 & 0.0258 & 0.0344 & 0.0301 \\
DBW & 0.0289 & 0.0330 & 0.0330 & 0.0289 & 0.0330 & 0.0371 & 0.0247 & 0.0330 \\
NWA & 0.0483 & 0.0552 & 0.0552 & 0.0552 & 0.0552 & 0.0483 & 0.0621 & 0.0483 \\
WSP & 0.0128 & 0.0112 & 0.0128 & 0.0128 & 0.0144 & 0.0128 & 0.0128 & 0.0112 \\
WDU & 0.0151 & 0.0177 & 0.0177 & 0.0202 & 0.0202 & 0.0177 & 0.0227 & 0.0177 \\
DTS & 0.0179 & 0.0201 & 0.0179 & 0.0156 & 0.0201 & 0.0156 & 0.0156 & 0.0156 \\
TBL & 0.0323 & 0.0251 & 0.0287 & 0.0251 & 0.0251 & 0.0287 & 0.0251 & 0.0251 \\
WQU & 0.0201 & 0.0230 & 0.0201 & 0.0201 & 0.0259 & 0.0201 & 0.0230 & 0.0201 \\
COE & 0.0252 & 0.0224 & 0.0224 & 0.0224 & 0.0252 & 0.0196 & 0.0224 & 0.0196 \\
SHD & 0.0227 & 0.0227 & 0.0227 & 0.0259 & 0.0194 & 0.0292 & 0.0227 & 0.0227 \\
TOP & 0.0439 & 0.0342 & 0.0390 & 0.0342 & 0.0342 & 0.0390 & 0.0342 & 0.0342 \\
PRL & 0.0368 & 0.0420 & 0.0368 & 0.0368 & 0.0473 & 0.0368 & 0.0420 & 0.0368 \\
LBR & 0.0171 & 0.0152 & 0.0152 & 0.0152 & 0.0171 & 0.0133 & 0.0152 & 0.0133 \\
\hline
\end{tabular}




\section{Results and Discussion}

The MCDM model has been applied to various fields of science and technology, and its use has increased over the years. One of the areas in which this model has been applied is the location selection process, but few have considered this issue in the wave energy power plant location selection. This is the main reason why this study proposes an MCDM model for wave power plant site selection.

In the first stage of this research, all criteria affecting location selection were determined by experts and literature reviews, and the FANP method was utilized to identify the weight of all criteria in the second stage. The ANP was proposed to overcome the problem of interdependence and feedback between criteria on alternatives. The ANP is the general form of the AHP, which has been used in the MCDM model to release the restrictions of hierarchical structures. However, human judgment varies from person to person, as human perception always contains a certain degree of vagueness and ambiguity. Using such language, decision-makers quantify uncertain events and objects. Fuzzy theory enables decision-makers to tackle the ambiguities involved in the process of the linguistic assessment of the data. Subsequently, in fuzzy ANP, the linguistic assessment is converted to triangular fuzzy numbers. These triangular fuzzy numbers are used to build a pairwise comparison matrix for the ANP, and one can obtain the weights for attributes on each level. The TOPSIS model is a multicriteria decision analysis method, which is used for ranking potential sites in the final stage. TOPSIS is based on the concept that the chosen alternative should have the shortest geometric distance from the positive ideal solution (PIS) and the longest geometric distance from the negative ideal solution (NIS). Based on the results shown in Figure 3, Con Co (SITE3) is the optimal site for building a wave power plant in Vietnam because it has the highest-ranking score [11,23].

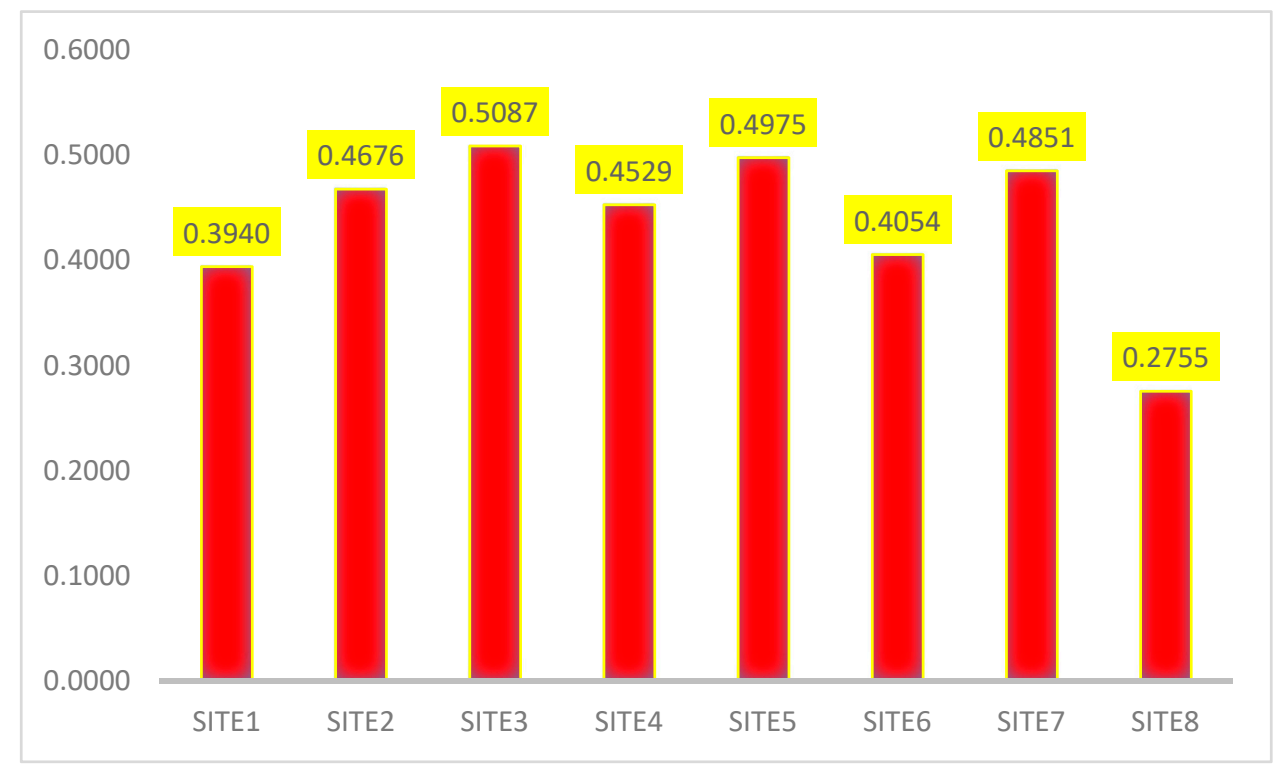

Figure 3. Final ranking score from the technique for order of preference by similarity to ideal solution (TOPSIS) model.

The contribution of this research is to propose a fuzzy MCDM model for site selection in the renewable energy sector under fuzzy environment conditions. The proposed model also can address different complex problems in location selection; further, it is a flexible design model for considering the evaluation criteria. Thus, it is applicable to site selection of other types of renewable energies in the world. 


\section{Conclusions}

In the context of increasing energy demand in Vietnam, the ability to supply domestic energy resources is limited, while the potential of renewable energy in Vietnam is great. In addition to the high demand for electricity for production, the availability of renewable energy sources for power generation is feasible both in technology and economic and environmental efficiency. Thus, many types of renewable energy resources are exploited in Vietnam. However, to compare with other countries in the world, the current results have not yet fully utilized Vietnam's potential. In order to meet demand while supplying energy faces many problems and challenges, especially with the gradual depletion of domestic fossil fuels, oil prices will fluctuate with increasing trends, and Vietnam will ultimately depend more on world energy prices. Therefore, considering the exploitation of renewable energy sources in the coming period will have important meaning, both economically and socially, for energy security and environmental protection.

This model has also been applied to the location selection process, but few studies have considered this issue in fuzzy environment conditions. This is a reason why the authors proposed the fuzzy multicriteria decision making (FMCDM) model for analyzing a suitable site for wave energy production by the FANP and TOPSIS model.

The limitation of this study is due to the specific nature of the energy investment sector, under the strict management of provisions of legislation. Therefore, the actual implementation process will take a long time.

For future research, this proposed model can be improved by considering more criteria that have an effect on the site selection process. In addition, variations in the MCDM model, such as FAHP, VlseKriterijumska Optimizacija I Kompromisno Resenje in Serbian (VIKOR), etc., can also be combined for future analysis.

Author Contributions: Conceptualization, C.-N.W. and C.-C.S.; Data curation, C.-N.W. and C.-C.S.; Funding acquisition, C.-N.W.; Methodology, C.-N.W., V.T.N., C.-C.S.; Project administration, C.-N.W., V.T.N.; Resources, C.-C.S.; Software, C.-C.S.; Writing—original draft, C.-C.S.; Writing—review and editing, C.-N.W., V.T.N.

Funding: This research was partly supported by National Kaohsiung University of Science and Technology, and project number 108-2622-E-992-017-CC3 from the Ministry of Sciences and Technology in Taiwan.

Conflicts of Interest: The authors declare no conflict of interest.

\section{References}

1. Minesto, Ocean Energy. Available online: https://minesto.com/ocean-energy (accessed on 12 January 2019).

2. Luan, M. Năng lượng sóng biển Việt Nam.Viet Bao. Available online: http://vietbao.vn/Khoa-hoc/Nangluong-song-bien-Viet-Nam/20886280/188/ (accessed on 12 January 2019).

3. Hien, N.; Nguyen, G.; Nguồn năng lượng khổng lồ trên biển Việt Nam. Tong Cong TY Dien Luc Mien Trung. Available online: https://cpc.vn/vi-vn/Tin-tuc-su-kien/Tin-tuc-chi-tiet/articleId/7565 (accessed on 12 January 2019).

4. Huang, J.; Poh, K.L.; Ang, B. Decision analysis in energy and environmental modeling. Energy 1995, 20, 843-855. [CrossRef]

5. Løken, E. Use of multicriteria decision analysis methods for energy planning problems. Renew. Sustain. Energy Rev. 2007, 11, 1584-1595. [CrossRef]

6. Triantaphyllou, E. Multi-Criteria Decision Making Methods: A Comparative Study; Springer: Boston, MA, USA, 2000.

7. Ghosh, S.; Chakraborty, T.; Saha, S.; Majumder, M.; Pal, M. Development of the location suitability index for wave energy production by ANN and MCDM techniques. Renew. Sustain. Energy Rev. 2016, 59, 1017-1028. [CrossRef]

8. Tilottama, C.; Majumder, M. Application of AHP in Location Selection of Wave Power Plant; IET: Hyderabad, India, 2018.

9. Astariz, S.; Iglesias, G. Selecting optimum locations for co-located wave and wind energy farms. Part I: The Co-Location Feasibility index. Energy Convers. Manag. 2016, 122, 589-598. [CrossRef] 
10. Ozkan, C.; Mayo, T. The renewable wave energy resource in coastal regions of the Florida peninsula. Renew. Energy 2019, 139, 530-537. [CrossRef]

11. Wang, C.N.; Nguyen, V.T.; Thai, H.T.N.; Duong, D.H. Multi-Criteria Decision Making (MCDM) Approaches for Solar Power Plant Location Selection in Viet Nam. Energies 2018, 11, 1504. [CrossRef]

12. Akkaş, Ö.P.; Erten, M.Y.; Çam, E.; Inanc, N. Optimal Site Selection for a Solar Power Plant in the Central Anatolian Region of Turkey. Int. J. Photoenergy 2017, 2, 1-13. [CrossRef]

13. Zubiate, L.; Villate, J.; Torre-Enciso, Y.; Soerensen, H.; Holmes, B.; Panagiotopoulos, M.; Neumann, F.; Rousseau, N.; Langston, D. Methodology for site selection for wave energy projects. In Proceedings of the 8th European Wave and Tidal, Uppsala, Sweden, 7-10 September 2009.

14. Vasileiou, M.; Loukogeorgaki, E.; Vagiona, D.G. GIS-based multi-criteria decision analysis for site selection of hybrid offshore wind and wave energy systems in Greece. Renew. Sustain. Energy Rev. 2017, 73, 745-757. [CrossRef]

15. Yang, C.; Chuang, S.; Huang, R. Location selection based on AHP/ANP approach. In Proceedings of the 2008 IEEE International Conference on Industrial Engineering and Engineering Management, Singapore, 8-11 December 2008.

16. Azizi, A.; Malekmohammadi, B.; Jafari, H.R.; Nasiri, H.; Parsa, V.A. Land suitability assessment for wind power plant site selection using ANP-DEMATEL in a GIS environment: Case study of Ardabil province, Iran. Environ. Monit. Assess. 2014, 186, 6695-7009. [CrossRef] [PubMed]

17. Pamučar, D.; Gigović, L.; Bajić, Z.; Janošević, M. Location Selection for Wind Farms Using GIS Multi-Criteria Hybrid Model: An Approach Based on Fuzzy and Rough Numbers. Sustainability 2017, 9, 1315. [CrossRef]

18. Nasehi, S.; Karimi, S.; Jafari, H. Application of Fuzzy GIS and ANP for Wind Power Plant Site Selection in East. Comput. Res. Prog. Appl. Sci. Eng. 2018, 2, 116-124.

19. Ahsan, A.M.M.N.; Abdullah-Al-Mamun, M.; Talapatra, S.; Kader, M.A. A Fuzy-ANP extent analysis to assess and select location for wind power plant. In Proceedings of the 15th International Conference on Computer and Information Technology (ICCIT), Chittagong, Bangladesh, 20-23 December 2012.

20. Liao, S.K.; Hsu, H.Y.; Chang, K.L. A Hybrid Multiple Criteria Decision Making Model for Selecting the Location of Women's Fitness Centers. Math. Probl. Eng. 2018. [CrossRef]

21. Jaiswal, A.K.; Satheesh, T.A.; Pandey, K.; Kumar, P.; Saran, S. Geospatial multi-criteria decision based site suitability analysis for solid waste disposal using topsis algorithm. ISPRS Ann. Photogramm. Remote Sens. Spat. Inf. Sci. 2018, 4, 431-438. [CrossRef]

22. Konstantinos, L.I.; Georgios, T.; Garyfallos, A.; Zacharoula, A.; Eleni, Z. A spatial decision support system framework for the evaluation of biomass energy production locations: Case study in the regional unit of drama, Greece. Sustainability (Switzerland) 2018, 10, 531.

23. Wang, C.N.; Huang, Y.F.; Chai, Y.C.; Nguyen, V.T. A Multi-Criteria Decision Making (MCDM) for Renewable Energy Plants Location Selection in Vietnam under a Fuzzy Environment. Appl. Sci. 2018, 8, 2069. [CrossRef]

24. Konstantinos, I.; Georgios, T.; Garyfalos, A. A Decision Support System methodology for selecting wind farm installation locations using AHP and TOPSIS: Case study in Eastern Macedonia and Thrace region, Greece. Energy Policy 2019, 132, 232-246. [CrossRef]

25. Asl-Rousta, B.; Mousavi, S.J. A TOPSIS-Based Multicriteria Approach to the Calibration of a Basin-Scale SWAT Hydrological Model. Water Resour. Manag. 2019, 33, 439-452. [CrossRef]

26. Erbaş, M.; Kabak, M.; Özceylan, E.; Çetinkaya, C. Optimal siting of electric vehicle charging stations: A GIS-based fuzzy Multi-Criteria Decision Analysis. Energy 2018, 163, 1017-1031.

27. Zadeh, L.A. Fuzzy sets. Inf. Control 1965, 8, 338-353. [CrossRef]

28. Toán, D.V. NĂNG LỰ̛NG TÁI TẠO TRÊN BIỂN VÀ ĐỊNH HỨ̛NG PHÁT TRIỂN TẠI VIỆT NAM; Viện Nghiên cứu biển và hải đảo: Ha Noi, Vietnam, 2010.

(C) 2019 by the authors. Licensee MDPI, Basel, Switzerland. This article is an open access article distributed under the terms and conditions of the Creative Commons Attribution (CC BY) license (http://creativecommons.org/licenses/by/4.0/). 